\title{
Comparison of bipolar hemiarthroplasty and total hip arthroplasty for displaced femoral neck fractures in the healthy elderly: a meta-analysis
}

\author{
Feng Wang ${ }^{\dagger}$, Haifei Zhang ${ }^{\dagger}$, Zhiyu Zhang ${ }^{*}$, Chengbin Ma and Ximin Feng
}

\begin{abstract}
Background: Displaced femoral neck fractures (FNFs) in healthy elderly patients have traditionally been managed with hemiarthroplasty (HA) or total hip arthroplasty (THA), with studies suggesting that THA may be the better option. However, it has recently been reported that bipolar HA (BHA) also provides good outcomes, and it is not clear as to whether BHA or THA is most appropriate. The purpose of this study was to conduct a meta-analysis of randomized controlled trials (RCTs) comparing the outcomes of BHA with THA for treating FNF in healthy elderly patients.
\end{abstract}

Methods: We searched the following databases from inception to May 2015 for relevant RCTs without language restrictions: PubMed, the Cochrane Central Register of Controlled Trials, Ovid MEDLINE and EMBASE, CINAHL, the China Biological Medicine Database, International Clinical Trials Registry Platform, Current Controlled Trials, and ClinicalTrials.gov. RCTs that met the inclusion criteria were statistically analyzed using the Cochrane review methods.

Results: Eight RCTs were included (total 1,014 patients; 523 had BHA and 491 had THA). The data from included RCTs were divided into four subgroups according to different follow-up durations. The Harris Hip Score after BHA was not different from that after THA in all subgroups. Both reoperation rate and acetabular erosion rate were higher after BHA after more than 4 years, while there was a higher dislocation rate associated with THA within 4 years. THA was more favorable regarding the $\mathrm{EQ}_{\text {index }}-5 \mathrm{D}$ and the mobility and pain rate, while $\mathrm{BHA}$ was more favorable regarding operating time. No significant differences were found regarding infection rate, general complications, 1-year mortality, blood loss, and length of postoperative hospital stay.

Conclusions: For healthy elderly patients with displaced FNFs, treatment with BHA led to better outcomes regarding dislocation rate, while THA was better regarding acetabular erosion rate and reoperation rate. When comparing BHA with THA, there were no significant differences in other important outcomes such as Harris Hip Score, infection rate, general complications, and 1-year mortality. Further high-quality RCTs are needed to provide robust evidence and evaluate the treatment options.

\section{Background}

The proportion of elderly people is increasing as the world's population ages, resulting in an expected rise in the incidence of osteoporotic hip fractures. It is estimated that about 1.6 million hip fractures occurred in the year 2000 [1], and the incidence of hip fractures is expected to increase to over six million worldwide by

\footnotetext{
*Correspondence: zhangzhiyudr_cmu4h@163.com

${ }^{\dagger}$ Equal contributors

Department of Orthopedics, the Fourth Affiliated Hospital of China Medical University, Chongshan Road, Shenyang 110032, Liaoning, People's Republic of China
}

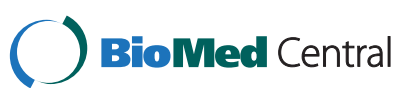

(C) 2015 Wang et al. Open Access This article is distributed under the terms of the Creative Commons Attribution 4.0 International License (http://creativecommons.org/licenses/by/4.0/), which permits unrestricted use, distribution, and reproduction in any medium, provided you give appropriate credit to the original author(s) and the source, provide a link to the Creative Commons license, and indicate if changes were made. The Creative Commons Public Domain Dedication waiver (http://creativecommons.org/publicdomain/zero/1.0/) applies to the data made available in this article, unless otherwise stated. the year 2050 [2]. About half of the hip fracture population has displaced femoral neck fracture (FNF, Garden type III or IV) of the subcapital region [3]; displaced FNFs can result in non-union or avascular necrosis [4]. Moreover, these fractures are associated with impaired mobility, loss of function, and personal dependence as well as with global economic health costs, and are significant causes of mortality and morbidity in the elderly $[5,6]$. The optimal treatment of displaced FNF in the elderly is an ongoing scientific and clinical debate [7].

Surgical treatment options for displaced FNF include internal fixation, which is not recommended in elderly 
patients [8-11], and arthroplasty. Both hemiarthroplasty (HA) and total hip arthroplasty (THA) are widely accepted methods of hip replacement after displaced FNF. Some evidence has suggested that THA leads to better functional outcome than HA [7]; however, there are some advantages of HA compared with THA such as reduced dislocation rate, less complex surgery, shorter operation time, less blood loss, and lower initial costs [12].

The prosthesis and the acetabulum in HA can be articulated using a unipolar or bipolar prosthesis. Parker et al. reported no difference in outcome between bipolar and unipolar prostheses in adults [7]. However, recent studies have reported that bipolar HA (BHA) provides good outcomes for elderly patients with displaced FNFs. BHA after FNF has predictable and good medium- and long-term results, even when compared with internal fixation or unipolar HA $[8,13,14]$, and BHA displays a later onset of acetabular erosion compared with unipolar HA [14, 15]. A review of data from national registries supports the continued use of BHA for FNF in the elderly [16], implying that BHA should be the preferred treatment for elderly patients with displaced FNF. Elderly patients who receive BHA may also have a more favorable survival outcome compared with those who receive unipolar HA [17]. Additionally, in elderly patients with FNFs who were fit and physiologically young, uncemented BHA seemed to achieve better functional outcomes [18]. The clinical results from different groups cannot agree on whether to recommend BHA or THA [19-21].

Therefore, we performed a meta-analysis of randomized controlled trials (RCTs) published up to May 2015. The aim of this study was to evaluate the clinical outcomes of BHA compared with THA. The results will improve understanding of the treatment options for displaced FNFs in healthy elderly patients.

\section{Methods}

Literature search

A protocol was developed prior to commencement of this meta-analysis following the Cochrane Back Review Group guidelines [22]. We searched the following databases from inception to May 2015 for relevant RCTs without language restrictions: PubMed, the Cochrane Central Register of Controlled Trials (CENTRAL), Ovid MEDLINE and EMBASE, CINAHL, the China Biological Medicine Database (CBM), International Clinical Trials Registry Platform (ICTRP), Current Controlled Trials, and ClinicalTrials.gov. Other search methods included screening references listed in relevant systematic reviews and identified RCTs, searching the abstracts of relevant meetings, and personal communication with content experts in the field and authors of identified RCTs. Key words used for searching were arthroplasty, hip prosthesis implantation, total hip replacement, bipolar hemiarthroplasty, hip fractures, femoral neck fracture, and randomized controlled trial.

\section{Study eligibility criteria}

All RCTs comparing BHA with THA for the treatment of FNF were considered for this review. Trials including participants with displaced FNFs (Garden type III or IV) in the elderly (older than 65 years) were eligible. Patients with the following conditions were excluded from the study: (1) undisplaced FNF; (2) pathological fracture secondary to malignant disease; (3) osteoarthritis or rheumatoid arthritis of the hip; (4) severe cognitive dysfunction; or (5) non-first time experience with artificial joint replacement.

The first phase of the trial selection process involved screening of titles and abstracts, followed by a second phase of eligibility evaluation from the full-text format. Both phases were performed independently by two reviewers and checked by the principal reviewer. The observed percentage agreement between the reviewers for the assessment of inclusion was calculated using the $\mathrm{k}$ test $[23,24]$. Disagreements were resolved by discussion.

\section{Risk of bias assessment and evaluation of validity}

The risk of bias (RoB) and methodological quality was assessed in duplicate using the Cochrane Collaboration recommendations, and evaluated independently by two reviewers [22, 25]. The criteria included six items as follows: (1) adequate sequence generation; (2) allocation concealment; (3) blinding; (4) incomplete outcome data; (5) selective reporting; and (6) other bias.

\section{Data extraction}

The data were extracted from included reports independently by two reviewers, and any disagreements were resolved through discussion. The data extracted included: participant characteristics, number of participants, and loss to follow-up; study characteristics; intervention details; primary and secondary outcomes. The primary outcomes included the Harris Hip Score (HHS) and reoperation rate. The secondary outcomes included: mobility, dislocation, acetabular erosion, infection, general complications, 1-year mortality, EuroQol $(\mathrm{EQ})_{\text {index }}-5 \mathrm{D}$ score, pain rate, operation time and blood loss, and length of hospital stay.

\section{Assessment of heterogeneity}

Heterogeneity was informally tested visually by the eyeball test, and formally tested by the chi-squared test and the $\mathrm{I}^{2}$ statistic; however, the decision regarding heterogeneity was dependent on $\mathrm{I}^{2}$. Substantial heterogeneity was defined as $\geq 50 \%$, and the effect of 


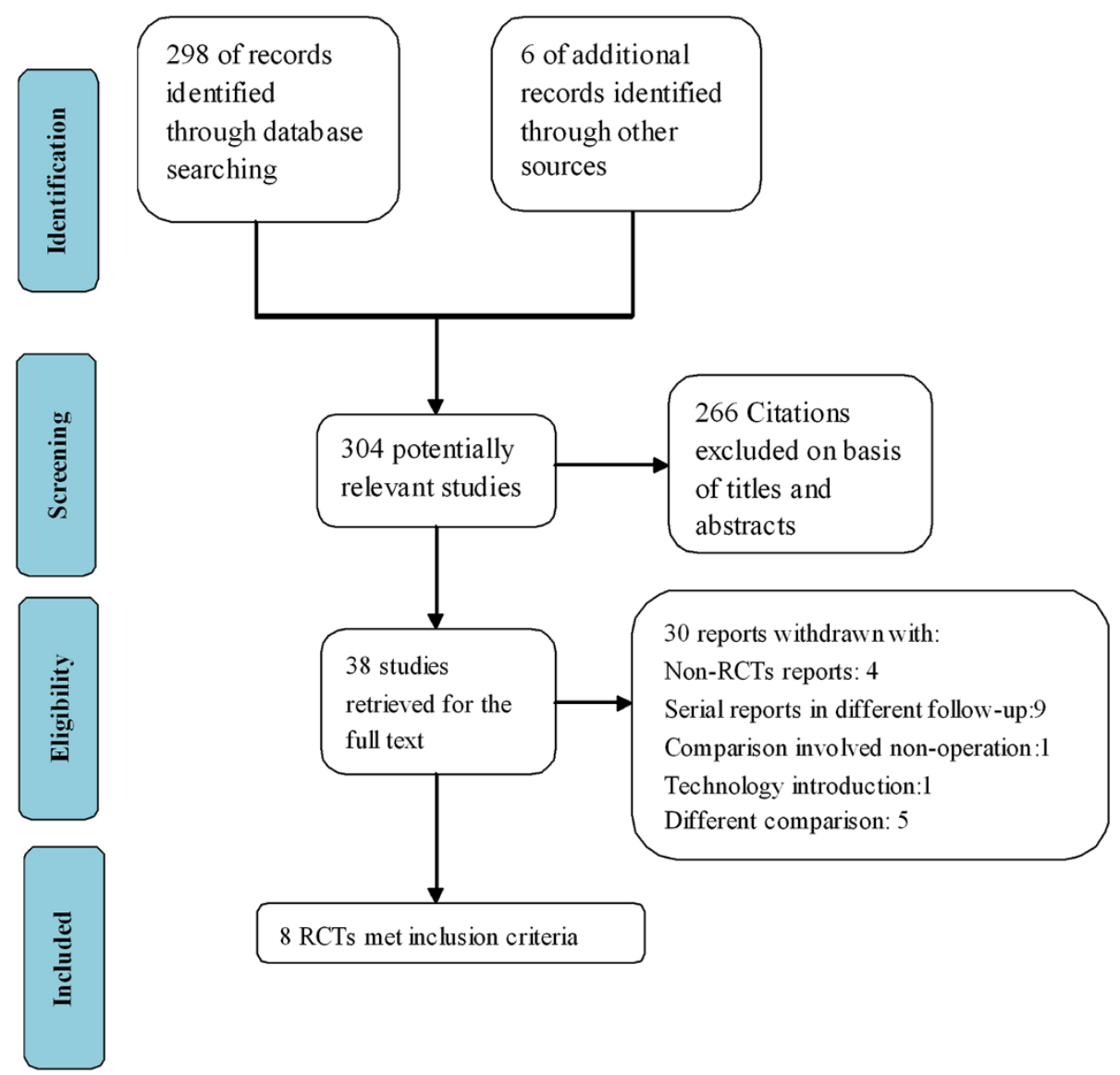

Fig. 1 PRISMA flow diagram of study selection

the interventions was described if the results were too heterogeneous.

\section{Measures of treatment effect}

Attempts were made to statistically pool the data of homogeneous studies in order to obtain the primary and secondary outcomes. The results were expressed in terms of risk ratio (RR) and $95 \%$ confidence intervals (95\% CI) for dichotomous outcomes, and in terms of weighted mean difference and $95 \%$ CI for continuous outcomes. When the same continuous outcomes were measured by different scales, the standardized mean difference and $95 \%$ CI were calculated. The individual and pooled statistics were calculated using the random effect model. Funnel plots were used to explore potential publication bias. The Cochrane Review Manager software (RevMan version 5.1, the Nordic Cochrane Centre, København, Denmark) software was used for data analysis.

Table 1 Overview of included trials

\begin{tabular}{|c|c|c|c|c|c|c|c|}
\hline 1st Author, publication year & $\begin{array}{l}\text { Country } \\
\text { conducted }\end{array}$ & $\begin{array}{l}\text { Preoperative } \\
\text { diagnosis }\end{array}$ & Comparisons & Sample size T/C & Female (\%) & Mean age(year) T/C & $\begin{array}{l}\text { Follow-up } \\
\text { (month) }\end{array}$ \\
\hline Dorr LD 1986 & United States & Displaced FNF & THA vs. BHA & $39 / 50$ & 65.17 & $69 / 69$ & $24-48$ \\
\hline Ravikumar 2000 & United Kingdom & Displaced FNF & THA vs. BHA & $89 / 91$ & 90 & $81.03 / 82.06$ & $>48$ \\
\hline Keating 2005 & United Kingdom & Displaced FNF & THA vs. BHA & $69 / 69$ & 76.8 & $75.2 / 75.0$ & 24 \\
\hline Baker 2006 & United Kingdom & Displaced FNF & THA vs. BHA & $40 / 41$ & 79.01 & $74.2 / 75.83$ & $30-68$ \\
\hline Mouzopoulos 2008 & Greece & Displaced FNF & THA vs. BHA & $37 / 34$ & 73.23 & $73.07 / 74.24$ & 48 \\
\hline van den Bekerom 2010 & Netherlands & Displaced FNF & THA vs. BHA & $115 / 137$ & 81 & $80.3 / 82.1$ & $>48$ \\
\hline Hedbeck 2011 & Sweden & Displaced FNF & THA vs. BHA & $60 / 60$ & 84.17 & $80.5 / 80.7$ & 48 \\
\hline Cadossi,2013 & Italy & Displaced FNF & THA vs. BHA & $42 / 41$ & 74.7 & $82.3 / 84.2$ & 36 \\
\hline
\end{tabular}




\section{Results}

Search results

The primary search identified 304 records, with 266 publications immediately excluded based on title and abstract screening. From the remaining 38 publications identified as potentially relevant, 30 were omitted according to the inclusion and exclusion criteria. A final total of eight trials $[12,19,26-31]$ were included in the meta-analysis (Fig. 1). The $\mathrm{\kappa}$ statistic for interrater agreement regarding study eligibility was 0.81 .

The eight RCTs eligible for inclusion involved a total of 1,014 patients, with individual sample sizes ranging from 81 to 252 patients. All studies in our meta-analysis were written in English, and were published between 1986 and 2013. The follow-up period ranged from 12 months to 13 years. Each included RCT presented baseline demographic data such as age, sex, and race. The characteristics of these studies are presented in Table 1.

\section{Methodological quality of included studies}

The results of the RoB assessment for the included studies are summarized in Fig. 2. Five studies had adequate methods of randomization [12, 19, 28, 30,31], and two

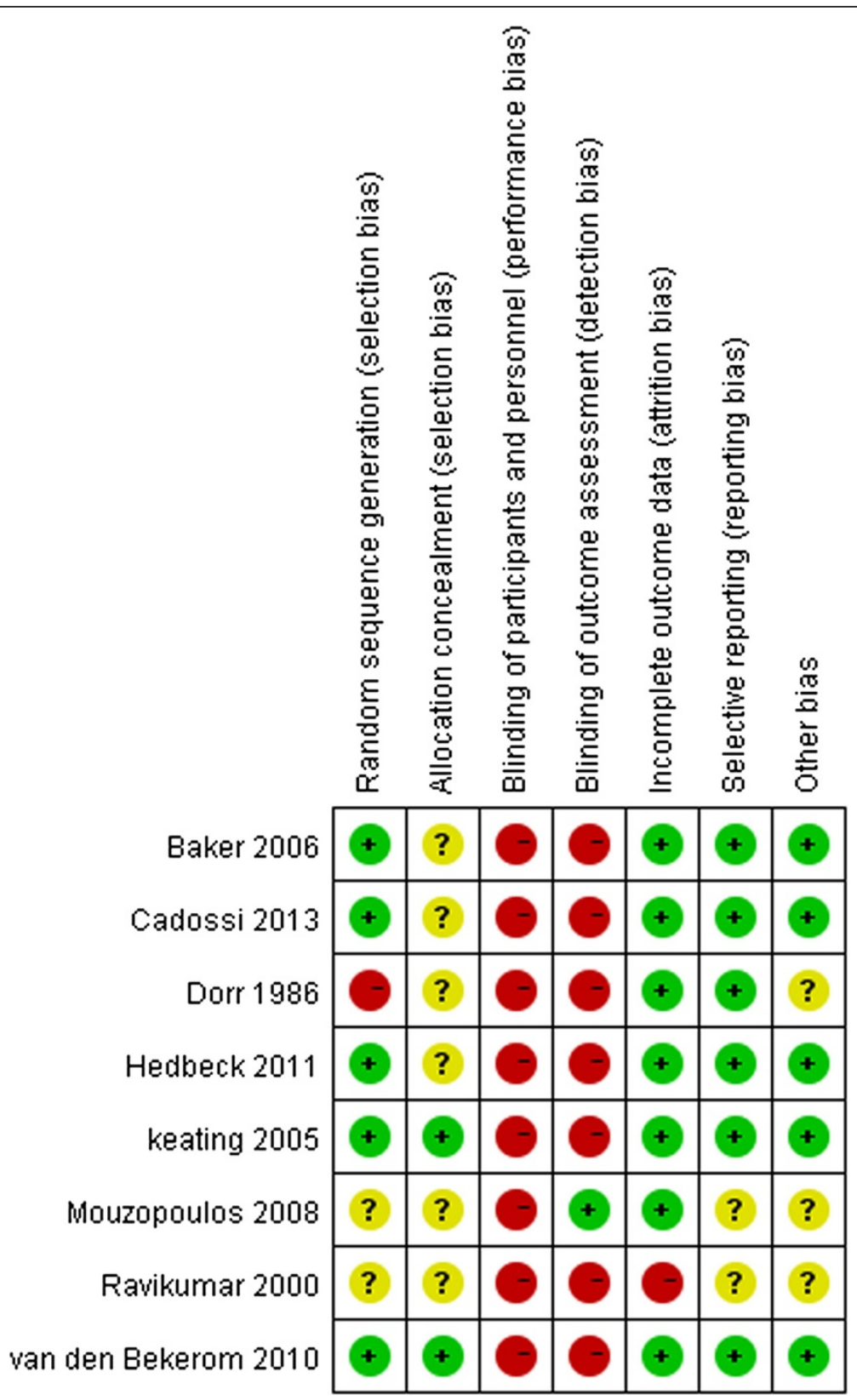

Fig. 2 Risk of bias assessment summary of included studies 


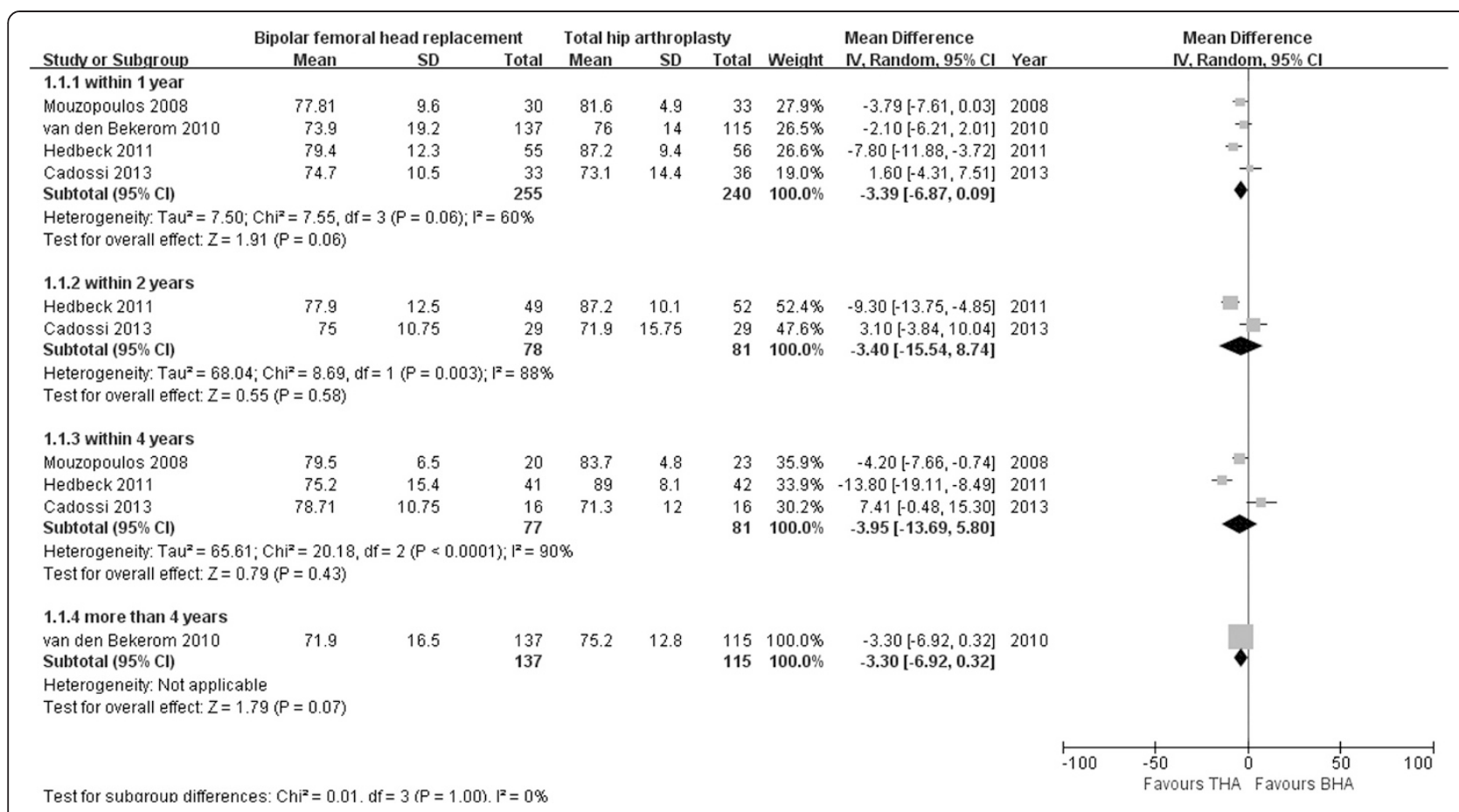

Fig. 3 Forest plot of Harris hip scores after bipolar hemiarthroplasty compared with those after total hip arthroplasty

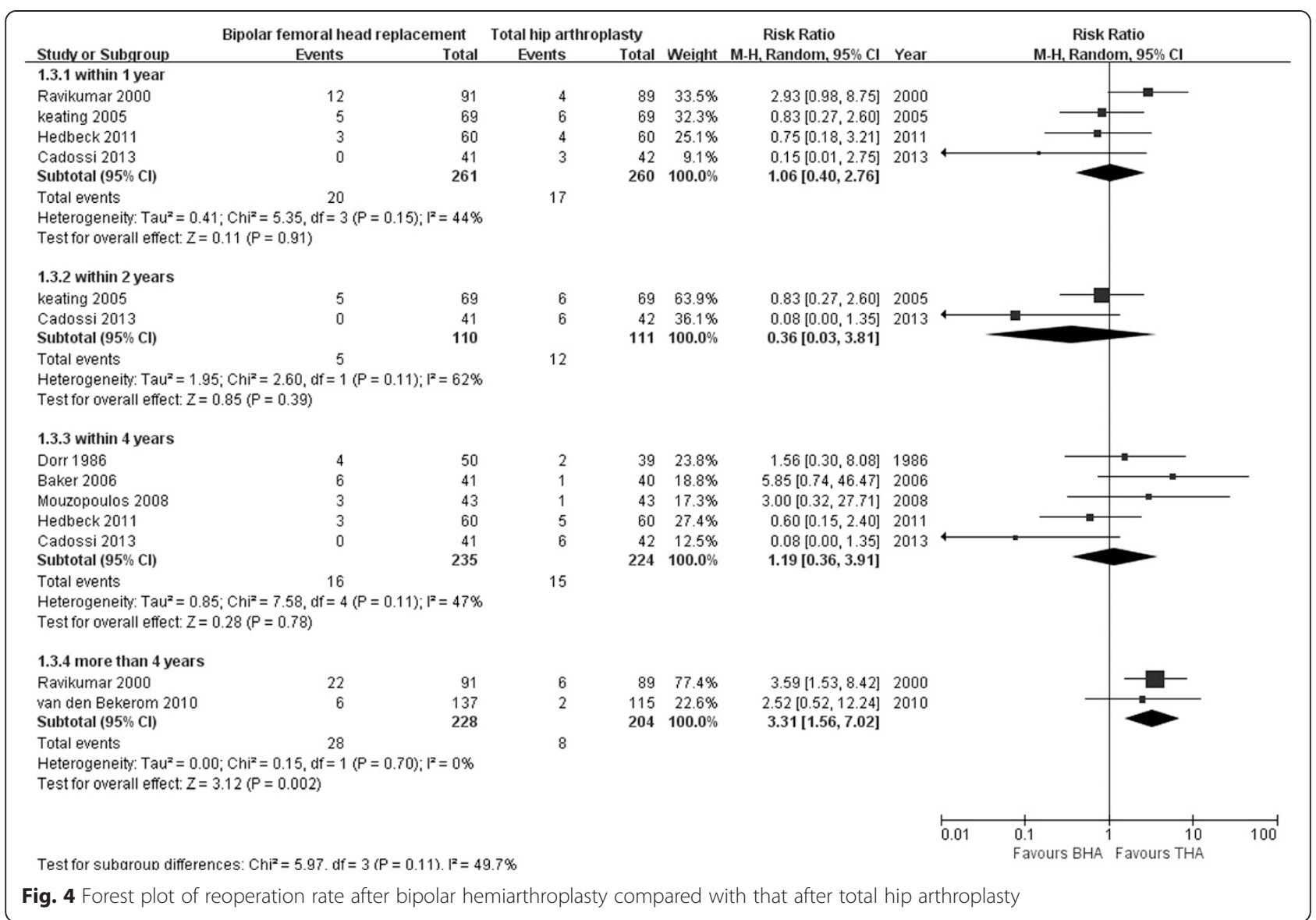




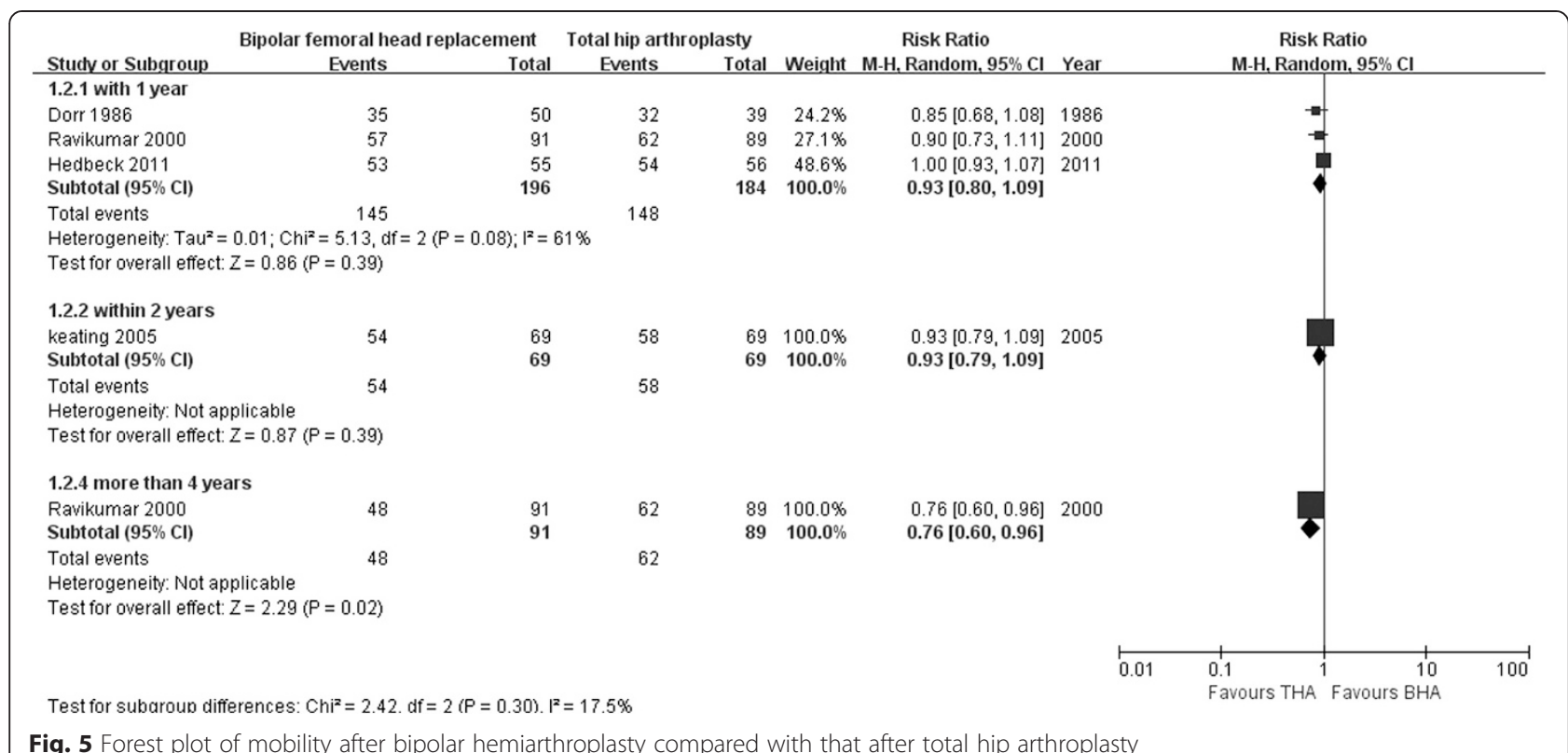

studies used an adequate sequence generation and allocation procedure [12, 19]. Both randomization and allocation were unclear in two included studies [27, 29]. None of the included studies attempted to blind the patients or surgeon as this was impossible owing to the nature of the surgery; one study compensated for the lack of blinding by using blinded observers to assess the outcome [29]. Most of the included studies provided an adequate overview of withdrawals or dropouts, and were able to keep these to a minimum for the subsequent

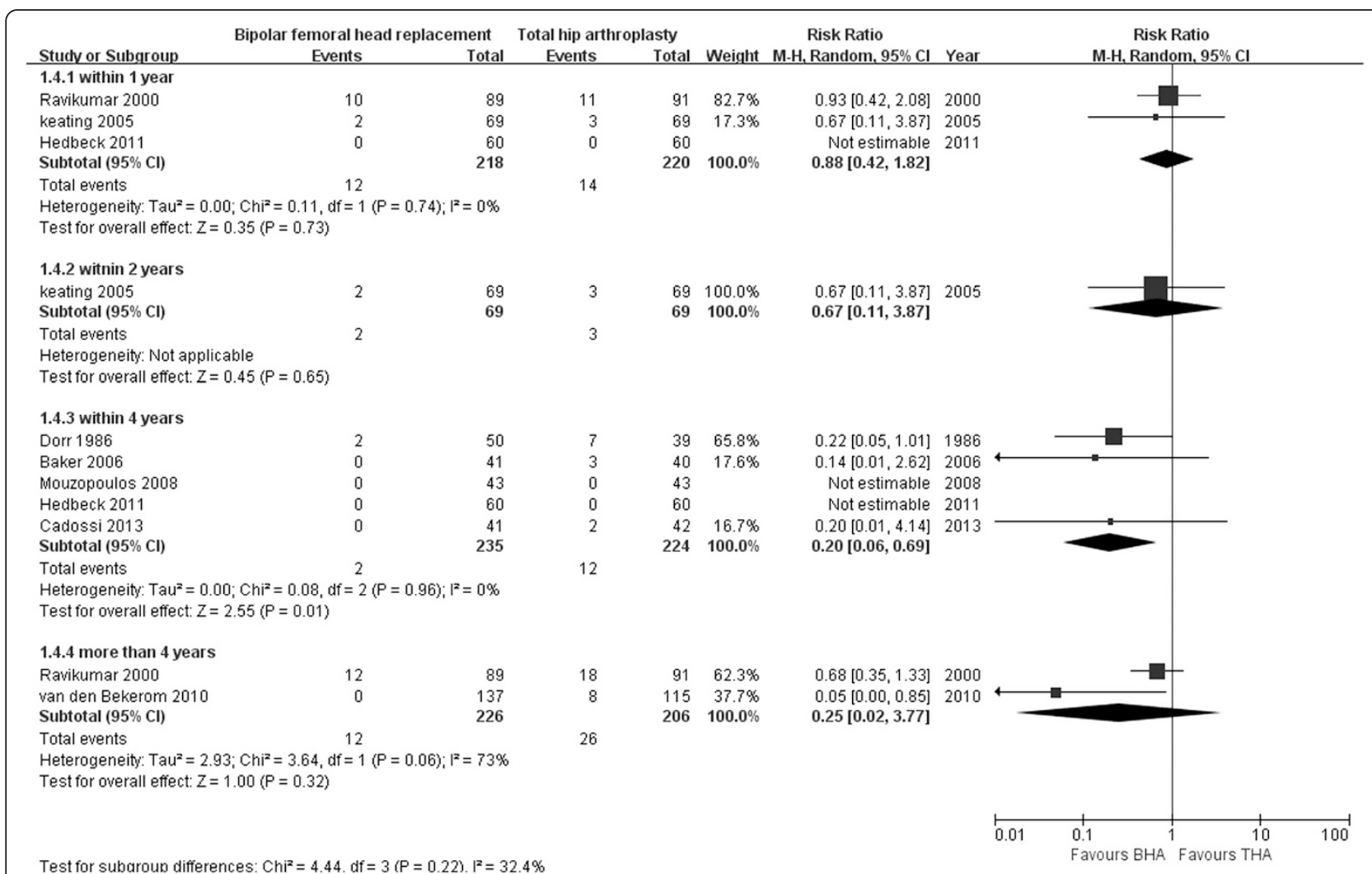

Fig. 6 Forest plot of dislocation rate after bipolar hemiarthroplasty compared with that after total hip arthroplasty 


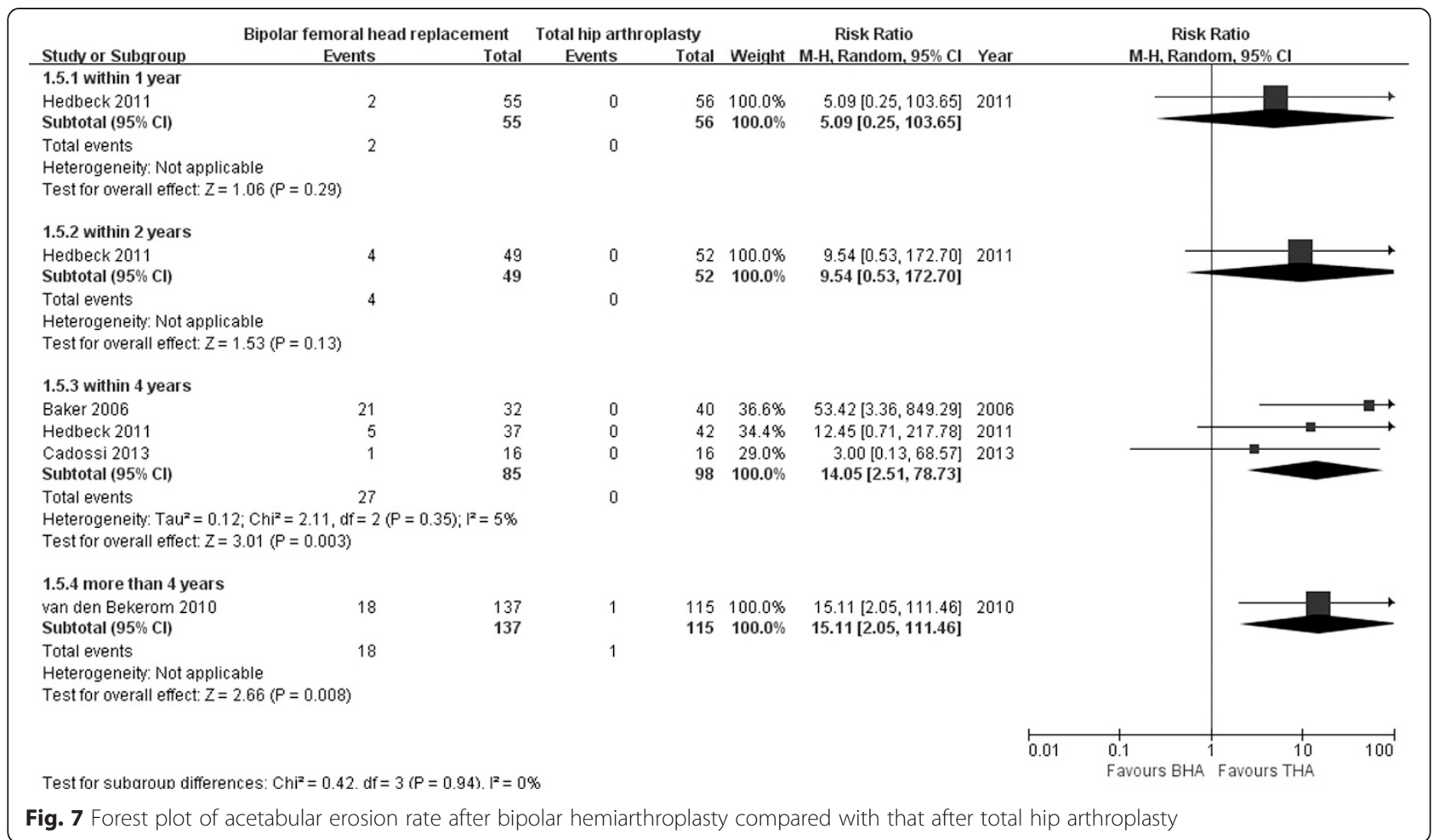

follow-up measurements, although only two studies conducted long-term follow-up [19, 27]. Published or registered protocols were unavailable for all studies, even after we conducted a comprehensive search. In the absence of these, it was difficult for us to decide whether outcomes were measured, or not reported because they were found to be insignificant or unfavorable. Therefore, six included studies that reported most primary outcomes were considered to have fulfilled this criterion [12, 19, 26, 28, 30, 31].

\section{Quantitative data synthesis of the primary outcomes Harris hip score}

The HHS is frequently used to assess the clinical outcome of total hip replacement. We selected it as the primary outcome owing to its high validity and reliability. Four studies assessed the HHS after BHA compared with THA within 1 year of follow-up (255 with BHA versus 240 with THA) [19, 29-31]; no significant differences were found (MD -3.39; $95 \%$ CI -6.87 , $0.09 ; p=0.06$ ), and heterogeneity across the studies was obvious $\left(\mathrm{I}^{2}=60 \%\right)$. Two studies assessed the HHS after BHA compared with THA within 2 years of follow-up (78 with BHA versus 81 with THA) [30, 31]; again no significant differences were found (MD -3.40; $95 \%$ CI $-15.54,8.74 ; p=0.58$ ), and heterogeneity across the studies was obvious $\left(\mathrm{I}^{2}=88 \%\right)$. Three studies assessed the HHS after BHA compared with THA within 4 years of follow-up (77 with BHA versus 81 with THA) [29-31]; no significant differences were found (MD 3.95; $95 \%$ CI $-5.80,13.69 ; p=0.43$ ), and heterogeneity across the studies was obvious $\left(\mathrm{I}^{2}=90 \%\right)$. Only one study reported no significant differences in HHS after BHA compared with THA after 5 years of follow-up (MD 3.30; $95 \%$ CI $-0.32,6.92 ; p=0.07$; Fig. 3) [19].

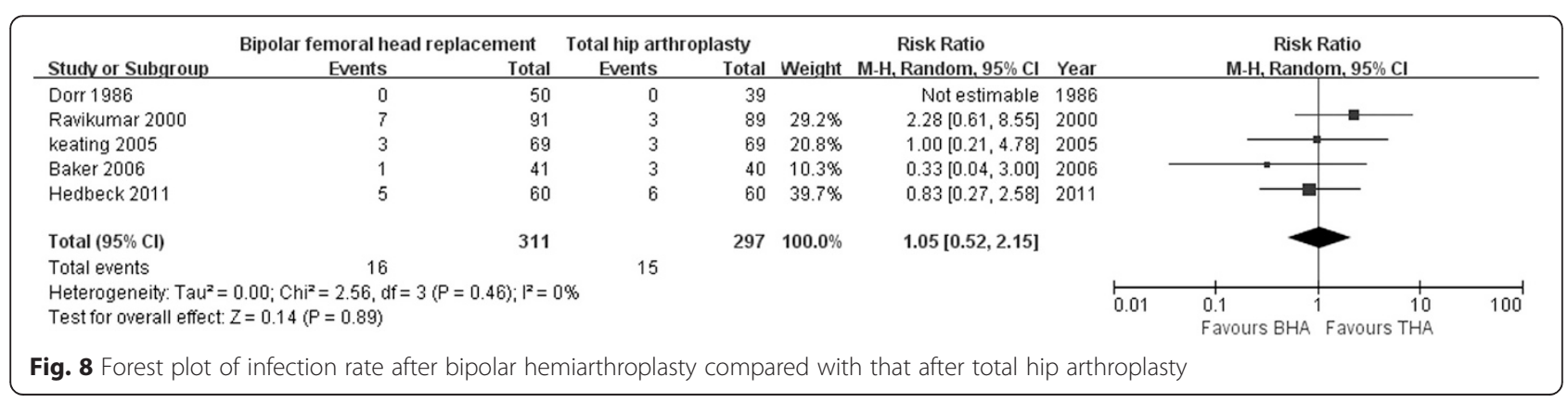




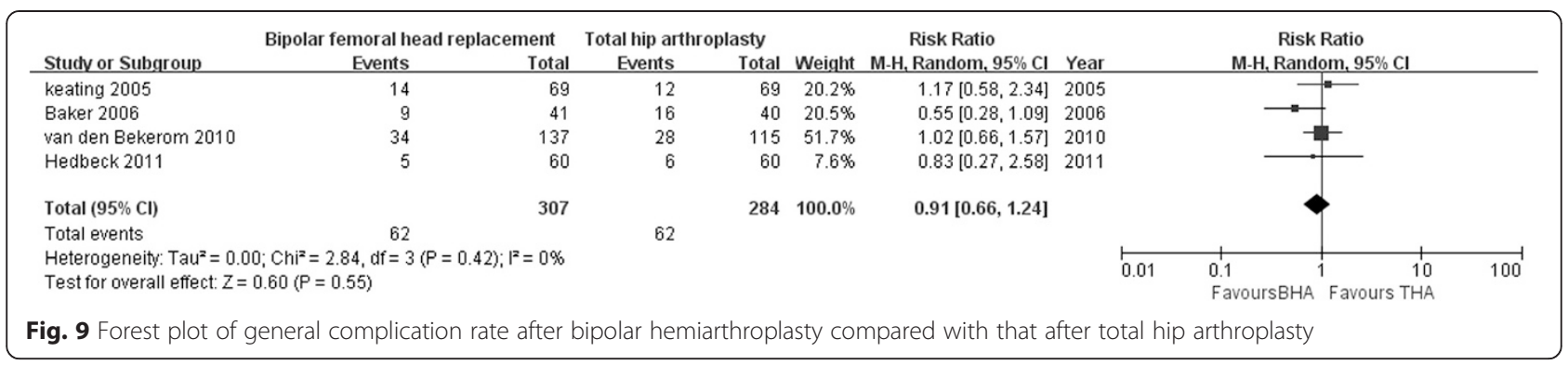

\section{Reoperation rate}

Four studies assessed the reoperation rate after BHA compared with THA within 1 year of follow-up (261 with BHA versus 260 with THA) [12, 27, 30, 31]; no significant differences were found (RR 1.06; $95 \% \mathrm{CI}$ $0.40-2.76 ; p=0.91)$, and there was no heterogeneity across the studies $\left(\mathrm{I}^{2}=44 \%\right)$. Two studies assessed the reoperation rate after $\mathrm{BHA}$ compared with THA within 2 years of follow-up (110 with BHA versus 111 with THA) [12, 31]; no significant differences were found (RR 0.36; $95 \%$ CI 0.03-3.81; $p=0.39$ ), but heterogeneity across the studies was obvious $\left(\mathrm{I}^{2}=62 \%\right)$. Five studies assessed the reoperation rate after BHA compared with THA within 4 years of follow-up (235 with BHA versus 224 with THA) [26, 28-31]; no significant differences were found (RR 1.19; $95 \%$ CI $0.36-3.91 ; p=0.78)$, and there was no heterogeneity across the studies $\left(\mathrm{I}^{2}=47 \%\right)$. Two studies reported that the reoperation rate after $\mathrm{BHA}$ was significantly greater than that after THA with more than 4 years of follow-up (228 with BHA versus 204 with THA; RR 3.31; $95 \%$ CI 1.56-7.02; $p=0.002 ; I^{2}=49.7 \%$; Fig. 4) [19, 27].

\section{Quantitative data synthesis of the secondary outcomes Mobility}

Three studies assessed the mobility rate after BHA compared with that after THA within 1 year of follow-up (196 with BHA versus 184 with THA) [26, 27, 30]; no significant differences were found (RR 0.93; $95 \%$ CI $0.80-1.09 ; p=0.39$ ), and heterogeneity across the studies was obvious $\left(\mathrm{I}^{2}=61 \%\right)$. One study showed similar results within 2 years of follow-up (RR 0.93; $95 \% \mathrm{CI}$ 0.79-1.09; $p=0$.39) [12]. However, another study reported significantly higher mobility rates after THA compared with BHA within 5 years of follow-up (RR 0.76; $95 \%$ CI 0.60-0.96; $p=0.02$; Fig. 5) [27].

\section{Dislocation rate}

Three studies assessed the dislocation rate after BHA compared with THA within 1 year of follow-up (218 with BHA versus 220 with THA) [12, 27, 30]; no significant differences were found (RR 0.88; $95 \%$ CI 0.42-1.82; $p=0.73)$, and there was no heterogeneity $\left(\mathrm{I}^{2}=0 \%\right)$. Only one study showed similar results for the dislocation rate after both procedures within 2 years of follow-up (RR $0.67 ; 95 \%$ CI $0.11-3.87 ; p=0.65$ ) [12]. Five studies reported a significantly greater dislocation rate after THA compared with BHA within 4 years of follow-up (RR 0.20; $95 \%$ CI 0.06-0.69; $p=0.01$ ), and there was no substantial heterogeneity between studies $\left(\mathrm{I}^{2}=0 \%\right)[26$, 28-31]. Two studies reported no significant difference in dislocation rate after BHA compared with that after THA after more than 4 years of follow-up (226 with BHA versus 206 with THA; RR 0.25; 95 \% CI 0.02-3.37; $p=0.32)$, and heterogeneity across the studies was obvious $\left(\mathrm{I}^{2}=73 \%\right.$; Fig. 6$)[19,27]$.

\section{Acetabular erosion rate}

One study reported no significant differences in acetabular erosion rate after BHA compared with that after THA within 1 year of follow-up (55 with BHA versus 56

\begin{tabular}{|c|c|c|c|c|c|c|c|c|c|c|c|}
\hline \multirow[b]{2}{*}{ Study or Subgroup } & \multicolumn{2}{|c|}{ Bipolar femoral head replacement } & \multicolumn{2}{|c|}{ Total hip arthroplasty } & \multicolumn{3}{|c|}{ Risk Ratio } & \multirow{2}{*}{\multicolumn{4}{|c|}{$\begin{array}{c}\text { Risk Ratio } \\
\text { M-H, Random, } 95 \% \mathrm{Cl}\end{array}$}} \\
\hline & Events & Total & Events & Total & Weight & M-H. Random, $95 \% \mathrm{Cl}$ & Year & & & & \\
\hline Dorr 1986 & 4 & 50 & 3 & 39 & $4.4 \%$ & $1.04[0.25,4.38]$ & 1986 & & & & \\
\hline Ravikumar 2000 & 25 & 91 & 21 & 89 & $36.6 \%$ & $1.16[0.71,1.92]$ & 2000 & & - & - & \\
\hline keating 2005 & 6 & 69 & 5 & 69 & $7.1 \%$ & $1.20[0.38,3.75]$ & 2005 & & & & \\
\hline Mouzopoulos 2008 & 13 & 43 & 10 & 43 & $18.3 \%$ & $1.30[0.64,2.64]$ & 2008 & & - & $=-$ & \\
\hline van den Bekerom 2010 & 18 & 137 & 16 & 115 & $23.4 \%$ & $0.94[0.50,1.77]$ & 2010 & & $\longrightarrow$ & - & \\
\hline Hedbeck 2011 & 3 & 60 & 4 & 60 & $4.3 \%$ & $0.75[0.18,3.21]$ & 2011 & & & & \\
\hline Cadossi 2013 & 8 & 41 & 3 & 42 & $5.8 \%$ & $2.73[0.78,9.58]$ & 2013 & & & & \\
\hline Total $(95 \% \mathrm{CI})$ & & 491 & & 457 & $100.0 \%$ & $1.16[0.86,1.57]$ & & & & $>$ & \\
\hline Total events & 77 & & 62 & & & & & & & & \\
\hline \multicolumn{3}{|c|}{$\begin{array}{l}\text { Heterogeneity: } \operatorname{Tau}^{2}=0.00 ; \mathrm{Ch}^{2}=2.68, \mathrm{df}=6(P=0.85) ; \mathrm{I}^{2}=0 \% \\
\text { Test for overall effect: } Z=0.98(P=0.33)\end{array}$} & & & & & & 0.01 & $\begin{array}{ll}0.1 & 1 \\
\text { Favours BHA }\end{array}$ & Favours THA & 100 \\
\hline
\end{tabular}




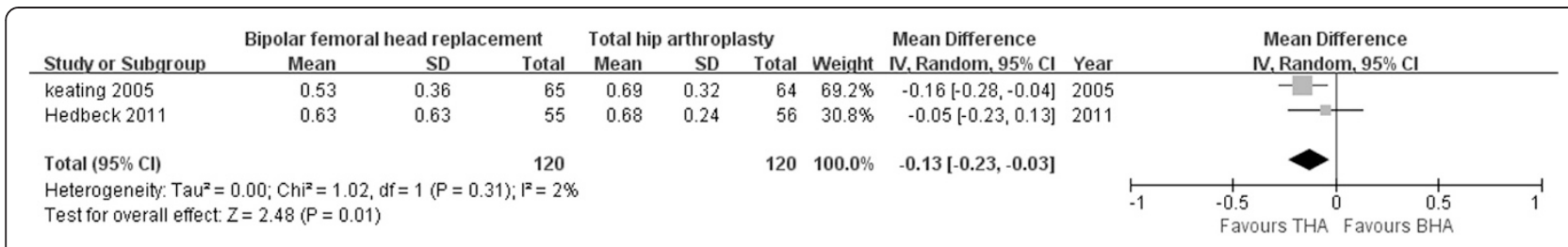

Fig. 11 Forest plot of EQ-5D scores after bipolar hemiarthroplasty compared with that after total hip arthroplasty

with THA; RR 5.09; $95 \%$ CI 0.25-103.65; $p=0.29$ ), and similar results were reported after 2 years of follow-up (RR 9.54; $95 \%$ CI 0.53-172.70; $p=0.13$ ) [30]. Three studies reported significantly higher acetabular erosion rates after BHA compared with that after THA within 4 years of follow-up (85 with BHA versus 98 with THA; RR 14.05; $95 \%$ CI 2.51-78.73; $p=0.003)$, and heterogeneity was minor $\left(\mathrm{I}^{2}=5 \%\right)[28,30,31]$. One study also reported significantly higher acetabular erosion rates after BHA compared with that after THA within 5 years of follow-up (RR 15.11; 95 \% CI 2.05-111.46; $p=0.008$; Fig. 7) [19].

\section{Infection}

The infection rate of the BHA group and the THA group was available in five studies (311 with BHA versus 297 with THA) [12, 26-28, 30]; no significant difference in infection rate was found between the two groups (RR $1.05,95 \%$ CI $0.52-2.15 ; p=0.89)$, and there was no substantial heterogeneity $\left(\mathrm{I}^{2}=0 \%\right.$; Fig. 8$)$.

\section{General complications}

Four studies assessed the general complication rate associated with BHA compared with that associated with THA (307 with BHA versus 284 with THA) [12, 19, 28, 30]; no significant differences were found (RR 0.91; $95 \%$ CI $0.66-1.24 ; p=0.55)$, and there was no substantial heterogeneity $\left(\mathrm{I}^{2}=0 \%\right.$; Fig. 9$)$.

\section{One-year mortality}

Seven studies assessed the 1-year mortality rate after BHA compared with that after THA (491 with BHA versus 457 with THA) [12, 19, 26, 27, 29-31]; no significant differences were found (RR 1.16; $95 \%$ CI 0.86-1.57; $p=0.33)$, and there was no substantial heterogeneity $\left(\mathrm{I}^{2}=0 \%\right.$; Fig. 10).

\section{Others}

$\mathrm{EQ}_{\text {index }}-5 \mathrm{D}$ scores were available from two included studies $[12,30]$. The pooled result showed a significant difference between the two procedures (MD -0.13; $95 \%$ CI $-0.23,0.13 ; p=0.01$; Fig. 11), with minor heterogeneity $\left(\mathrm{I}^{2}=2 \%\right)$. Some patients had significant hip pain after arthroplasty; two studies assessed the pain rate after BHA compared with that after THA, and reported a significantly lower pain rate after THA $(R R=1.44$; $95 \%$ CI 1.02-2.00; $p=0.03$; Fig. 12), but there was obvious heterogeneity between these studies $\left(\mathrm{I}^{2}=88 \%\right)$ $[12,27]$. Significant difference was found in the operating time for BHA compared with BHA in four trials, (MD -14.83; $95 \%$ CI $-28.11,-1.55 ; p=0.03$; Fig. 13), with obvious heterogeneity $\left(\mathrm{I}^{2}=91 \%\right)[12,28,30,31]$. A significant difference was found in the blood loss between the two procedures in one report ( $\mathrm{MD}-140.00$; $95 \%$ CI $-221.01,-58.99 ; p=0.0007$; Fig. 14) [30]. No significant difference was found in the length of hospital stay in three trials $[19,29,31]$ (MD $-0.51 ; 95 \%$ CI -1.87 , $0.86 ; p=0.47$; Fig. 15), and there was no substantial heterogeneity $\left(\mathrm{I}^{2}=0 \%\right)$.

\section{Publication bias}

No evidence of publication bias was found, and funnel plots were constructed for the HHS scores (Fig. 16). Although the funnel plots did not show substantial asymmetry, the impact of a possible publication bias cannot be excluded as the reliability of this kind of assessment is weak when a low number of studies are included.

\section{Discussion}

The latest meta-analysis comparing THA with HA found that THA was preferable for healthy elderly patients with displaced FNF, because of better functional

\begin{tabular}{|c|c|c|c|c|c|c|c|c|c|c|}
\hline \multirow[b]{2}{*}{ Study or Subgroup } & \multicolumn{2}{|c|}{ Bipolar femoral head replacement } & \multicolumn{2}{|c|}{ Total hip arthroplasty } & \multirow{2}{*}{ Weight } & \multirow{2}{*}{$\begin{array}{c}\text { Risk Ratio } \\
\text { M-H, Fixed, } 95 \% \mathrm{Cl}\end{array}$} & \multirow{2}{*}{\multicolumn{4}{|c|}{$\begin{array}{c}\text { Risk Ratio } \\
\text { M-H. Fixed, 95\% Cl}\end{array}$}} \\
\hline & Events & Total & Events & Total & & & & & & \\
\hline keating 2005 & 34 & 69 & 33 & 69 & $86.7 \%$ & $1.03[0.73,1.45]$ & & & & \\
\hline Ravikumar 2000 & 21 & 91 & 5 & 89 & $13.3 \%$ & $4.11[1.62,10.42]$ & & & & \\
\hline Total $(95 \% \mathrm{Cl})$ & & 160 & & 158 & $100.0 \%$ & $1.44[1.04,2.00]$ & & & & \\
\hline Total events & 55 & & 38 & & & & & & & \\
\hline \multicolumn{3}{|c|}{$\begin{array}{l}\text { Heterogeneity: } \mathrm{Chi}^{2}=8.51, \mathrm{df}=1(\mathrm{P}=0.004) ; \mathrm{I}^{2}=88 \% \\
\text { Test for overall effect: } Z=2.18(P=0.03)\end{array}$} & & & & & 0.01 & $\begin{array}{ll}0.1 & 1 \\
\text { Favours } & B H A\end{array}$ & $\begin{array}{r}10 \\
\text { Favours THA }\end{array}$ & 100 \\
\hline
\end{tabular}




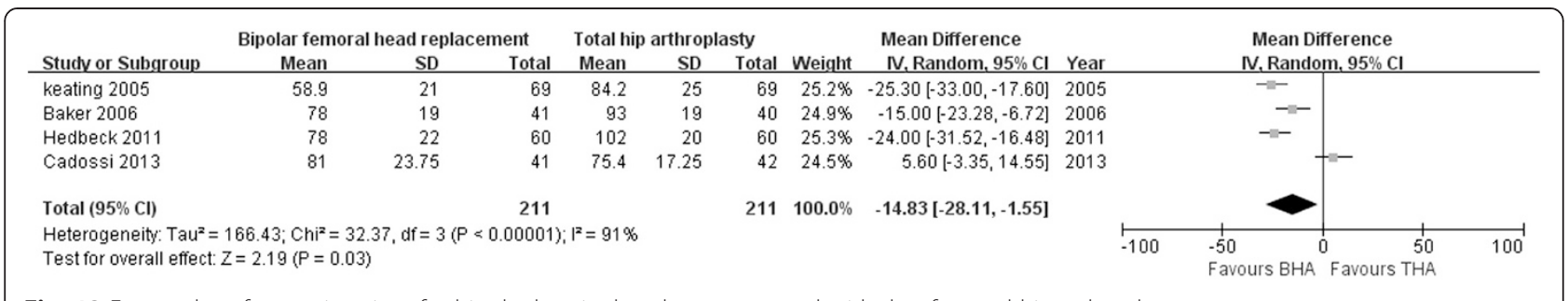

Fig. 13 Forest plot of operating time for bipolar hemiarthroplasty compared with that for total hip arthroplasty

outcomes and lower reoperation rates [32]. However, in the last several years some results have suggested that BHA results in a better clinical outcome than unipolar HA $[14,15,17]$, and that BHA should be the preferred treatment for elderly patients with displaced FNF [16]. There is still controversy over whether THA or BHA should be recommended in healthy elderly patients with displaced FNF.

Eight RCTs were included in the present analysis (total 1,014 patients; 523 with BHA versus 491 with THA). The different follow-up durations in the included studies meant that the data could not be directly pooled; thus the data were initially divided into four different subgroups (within 1 year, within 2 years, within 4 years, and more than 4 years). The results showed that the comparison of HHS was not different between BHA and THA in all subgroups, although HHS tended to be higher after THA. Both reoperation rate and acetabular erosion rates were higher after BHA after more than 4 years, while there was a higher risk of dislocation after THA. Some of the outcomes such as EQ index $-5 \mathrm{D}$, mobility and pain rate were in favor of THA, while operating time was in favor of BHA. No significant differences were found in other outcomes, including infection rate, general complication, 1-year mortality, blood loss, and length of postoperative hospital stay.

The present meta-analysis showed that HHS after THA was not significantly different from that after BHA in each subgroup; however, it tended to be higher after THA. It was reported in the last several meta-analyses that the HHS was higher after THA compared with HA [32-35]. The present meta-analysis included a newly reported high quality RCT in which the HHS after BHA was compared with that after polycarbonate-urethane (PCU)-THA within 3 years [31]. The PCU-THA comprised a PCU acetabular component coupled with a large- diameter metal femoral head for the treatment of displaced FNFs in elderly patients [31]. There were no significant differences between THA and BHA; however, the HHS tended to be higher in the BHA group than in the THA group within 3 years, and the authors suggested that the patients in the PCU-THA group experienced significantly more pain than the HA patients [31], which is one of the important factors affecting HHS [36]. These results might have influenced the pooled results in the present meta-analysis; therefore, we performed a sensitivity analysis by omitting this report. The subsequent results showed that the HHS in the THA group was better than that in the BHA group within 2 years, while the HHS was non-significantly higher in the THA group after 2 years. We suggest that, even though THA might lead to better clinical outcomes, proper implants were of great importance for the patients. Moreover, heterogeneity was obvious between studies, which might also have influenced the validity of the pooled results.

In the present meta-analysis, there were no significant differences between $\mathrm{BHA}$ and THA regarding reoperation rate within 4 years; however, the reoperation rate was higher after BHA than that after THA after 4 years. This result is similar to previous results [32, 33, 35, 37, 38]; however, it was different from the results of Kannan et al. [16]. Kannan et al. analyzed national registry data and reported a lower reoperation rate after $\mathrm{BHA}$ than after THA after a follow-up of 9 years in the Australian and Italian registries [16]. They concluded that the difference in reoperation rate after both procedures in Australia was not significant for patients under 75 years, but was significantly lower after BHA for those over 75 years and hence BHA may be better for this age group, considering the low functional demand and the morbidity of reoperation surgery in patients over 75 years of age [16].

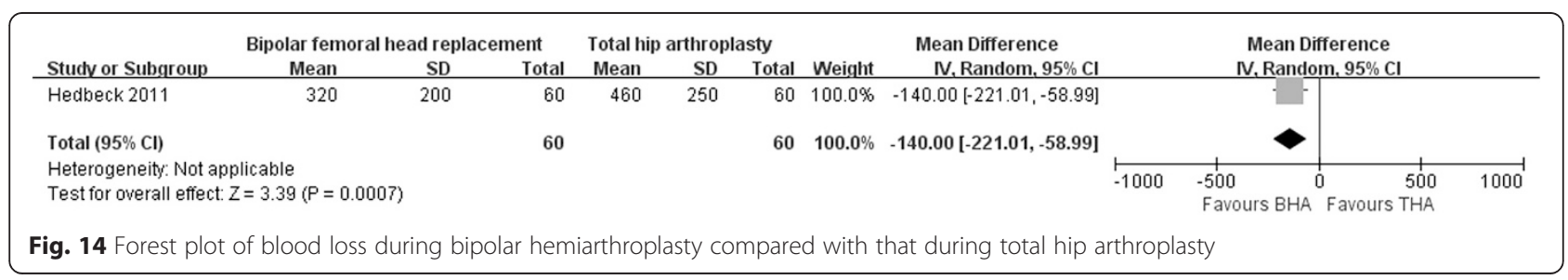




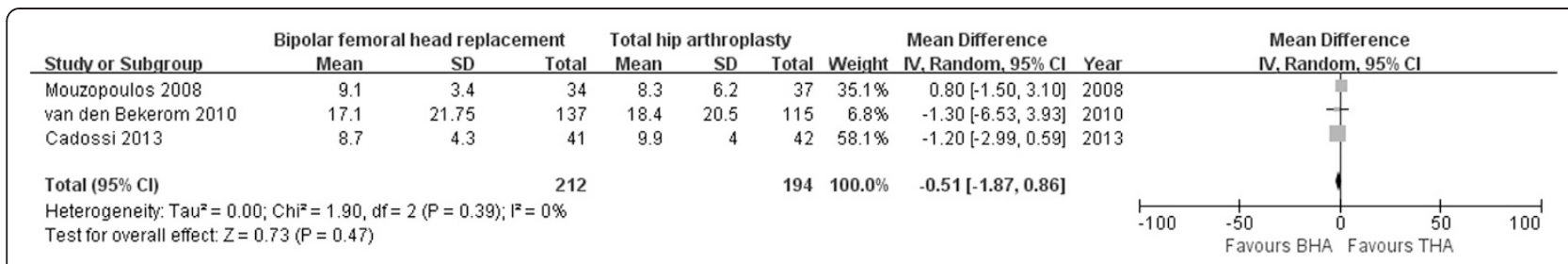

Fig. 15 Forest plot of length of hospital stay after bipolar hemiarthroplasty compared with that after total hip arthroplasty

There was a higher acetabular erosion risk after BHA than after THA, which often results in persistent pain [39-41] and reoperation after HA [42, 43]; this was even higher in unipolar HA $[14,15]$. HA may lead to conversion from HA to THA, and Coates and Armour advocated that THA should be used in cases of acetabular erosion with HA [44], while Kannan et al. suggested that using THA to prevent acetabular erosion is not supported by registry data [16], although a longer follow-up may change this recommendation. However, the reoperation rate for acetabular erosion after HA was very low $[16,45]$, and accurate and careful preoperative planning for HA to equalize limb lengths and restore the patient's own femoral offset can reduce postoperative acetabular erosion and pain [46]. Sen et al. introduced a new technique that was able to salvage a painful HA due to acetabular erosion [40].

One of the main reasons for reoperation after THA is dislocation [12]. In the present meta-analysis there was a higher dislocation risk after THA than after BHA, which was similar to previous reports [32-35, 37, 38]. Factors contributing to dislocation may include the surgical approach and the size of the prosthetic head. A multivariable analysis of dislocation after primary THA for all diagnoses found that a posterolateral approach and a smaller prosthetic head were associated with a higher rate of dislocation [47]. This was similar in BHA [16], hence choosing optimal hardware and improving the surgical access route may help to reduce complications associated with this common procedure. Enocson et al. analyzed the possible reasons related to dislocation in THA, and recommended the anterolateral approach for THA in patients with FNF to minimize the risk of dislocation [48]. Byström et al. studied the risk factors for prosthesis luxation leading to reoperation, and found that larger head size had been associated with fewer dislocations [49]. Therefore, an accurate and careful preoperative plan that considers the most appropriate approach and prosthesis may help lower the dislocation rate.

Our review has some limitations. First, the search was restricted to RCTs published in peer-reviewed journals, excluding other sources of biomedical literature that could have possibly provided more relevant studies. In such a case, studies with positive or statistically significant results would be expected to be over-represented in our review, as such studies were more likely to be published, particularly in the English language. To counter this, we used funnel plots to investigate the potential influence of publication bias on our results. Second, the validity of our results is limited by the low quality of the included studies; double-blinding was unattainable for

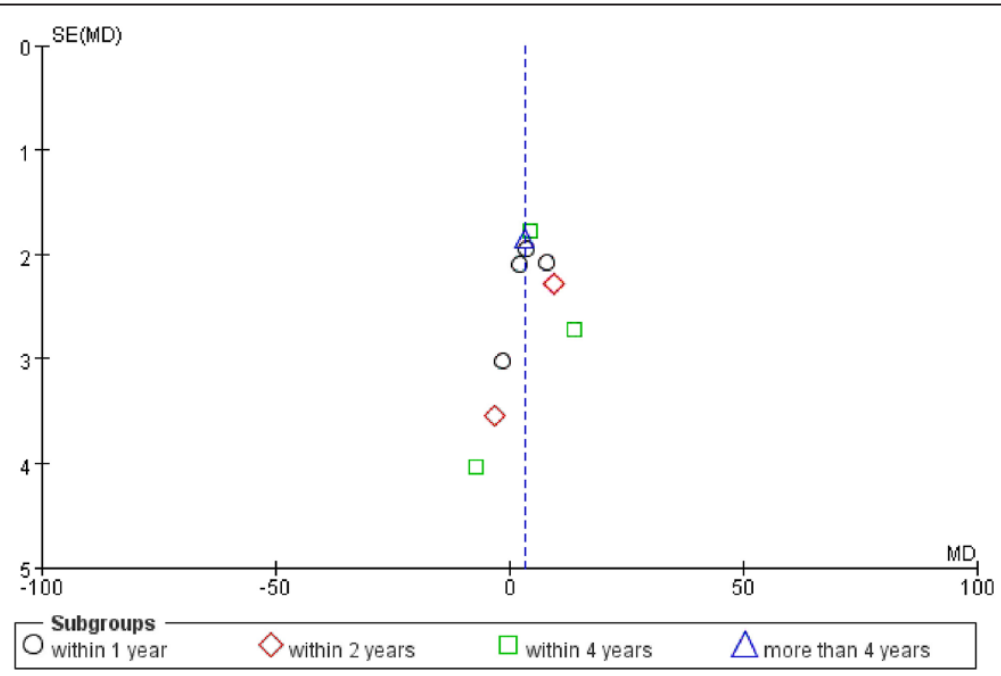

Fig. 16 Funnel plot of publication bias in terms of Harris hip scores after bipolar hemiarthroplasty compared with that after total hip arthroplasty 
most of the trials, which may decrease the strength of our conclusions. Third, there is the potential for bias because of high heterogeneity $(\geq 50 \%)$ in some comparisons, which may have affected the pooled results. Studies brought together in a meta-analysis will inevitability differ, and any kind of variability among studies may be termed heterogeneity. The included studies had clinical heterogeneity caused by variability in the participants (age, gender, comorbidities, preoperative ambulatory status), interventions (instrumentation from different manufacturers, different surgeons) and outcomes (selective reporting, data deficiency), and methodological heterogeneity caused by variability in study design and RoB.

However, there were several improvements in the present meta-analysis compared with previous reviews. This review is the most current report on the topic and includes the latest published trials. We adopted more strict inclusion criteria, with quasi-RCTs and non-RCTs strictly excluded in order to guarantee the reliability of results. We pooled most data of comparable parameters using subgroup analysis with different follow-up durations in an attempt to reduce the bias. We conducted this first analysis comparing BHA with THA to provide alternative guidelines for the clinical treatment of healthy elderly patients with FNF.

\section{Conclusions}

For the healthy elderly with displaced FNFs, BHA led to better outcomes regarding dislocation rate, while THA was more favorable regarding acetabular erosion rate and reoperation rate. There were no significant differences between BHA and THA in some other important outcomes such as HHS, infection rate, general complications, and 1-year mortality. Further high-quality RCTs are needed to provide robust evidence and evaluate the treatment options for displaced FNF in healthy elderly patients.

\section{Abbreviations \\ BHA: Bipolar hemiarthroplasty; CBM: China Biological Medicine Database; CENTRAL: Cochrane Central Register of Controlled Trials; Cl: Confidence interval; FNF: Femoral neck fracture; HA: Hemiarthroplasty; HHS: Harris hip score; ICTRP: International Clinical Trials Registry Platform; PCU: Polycarbonate- urethane; RCT: Randomized controlled trial; RoB: Risk of bias; RR: Risk ratio; THA: Total hip arthroplasty.}

\section{Competing interests}

The authors declare that they have no competing interests.

\section{Authors' contributions \\ FW, HFZ and ZYZ conceived and designed the study. FW, HFZ, ZYZ, CBM and XMF screened the literature search results and identified articles for retrieval, reviewed full papers for inclusion, and extracted data for meta-analysis. FW, HFZ and ZYZ analyzed data and carried out comparisons. FW and HFZ wrote the manuscript. All authors read and approved the final manuscript.}

\section{Acknowledgments}

No funding was received for this study or the writing of this manuscript.
Received: 17 March 2015 Accepted: 25 August 2015

Published online: 28 August 2015

\section{References}

1. Johnell O, Kanis JA. An estimate of the worldwide prevalence and disability associated with osteoporotic fractures. Osteoporos Int. 2006;17:1726-33.

2. De Laet CE, Pols HA. Fractures in the elderly: epidemiology and demography. Baillieres Best Pract Res Clin Endocrinol Metab. 2000;14:171-9.

3. Garden RS. Low-angle fixation in fractures of the femoral neck. J Bone Joint Surg. 1961;43:647-61.

4. Karaeminogullari O, Demirors $H$, Atabek M, Tuncay C, Tandogan R. Avascular necrosis and nonunion after osteosynthesis of femoral neck fractures: effect of fracture displacement and time to surgery. Adv Ther. 2004;21:335-42.

5. Cooper C, Campion G, Melton 3rd LJ. Hip fractures in the elderly: a worldwide projection. Osteoporos Int. 1992;2:285-9.

6. Cooper C, Atkinson EJ, Jacobsen SJ, O'Fallon WM, Melton 3rd LJ. Populationbased study of survival after osteoporotic fractures. Am J Epidemiol. 1993;137:1001-5.

7. Parker MJ, Gurusamy KS, Azegami S. Arthroplasties (with and without bone cement) for proximal femoral fractures in adults. Cochrane Database Syst Rev. 2010;6:CD001706.

8. Støen RØ, Lofthus CM, Nordsletten L, Madsen JE, Frihagen F. Randomized trial of hemiarthroplasty versus internal fixation for femoral neck fractures: no differences at 6 years. Clin Orthop Relat Res. 2014;472:360-7.

9. Chammout GK, Mukka SS, Carlsson T, Neander GF, Stark AW, Skoldenberg OG. Total hip replacement versus open reduction and internal fixation of displaced femoral neck fractures: a randomized long-term follow-up study. J Bone Joint Surg Am. 2012;94:1921-8.

10. Leonardsson O, Sernbo I, Carlsson A, Akesson K, Rogmark C. Long-term follow-up of replacement compared with internal fixation for displaced femoral neck fractures: results at ten years in a randomised study of 450 patients. J Bone Joint Surg (Br). 2010;92:406-12.

11. Gao H, Liu Z, Xing D, Gong M. Which is the best alternative for displaced femoral neck fractures in the elderly?: A meta-analysis. Clin Orthop Relat Res. 2012;470:1782-91.

12. Keating JF, Grant A, Masson M, Scott NW, Forbes JF. Displaced intracapsular hip fractures in fit, older people: a randomised comparison of reduction and fixation, bipolar hemiarthroplasty and total hip arthroplasty. Health Technol Assess. 2005;9:iii-iv. ix-x, 1-65.

13. Langslet E, Frihagen F, Opland V, Madsen JE, Nordsletten L, Figved W. Cemented versus uncemented hemiarthroplasty for displaced femoral neck fractures: 5-year follow up of a randomized trial. Clin Orthop Relat Res. 2014;472:1291-9.

14. Inngul C, Hedbeck CJ, Blomfeldt R, Lapidus G, Ponzer S, Enocson A. Unipolar hemiarthroplasty versus bipolar hemiarthroplasty in patients with displaced femoral neck fractures. A four-year follow-up of a randomised controlled trial. Int Orthop. 2013;37:2457-64.

15. Hedbeck CJ, Blomfeldt R, Lapidus G, Törnkvist H, Ponzer S, Tidermark J. Unipolar hemiarthroplasty versus bipolar hemiarthroplasty in the most elderly patients with displaced femoral neck fractures: a randomised, controlled trial. Int Orthop. 2011;35:1703-11.

16. Kannan A, Kancherla R, McMahon S, Hawdon G, Soral A, Malhotra R. Arthroplasty options in femoral-neck fracture: answers from the national registries. Int Orthop. 2012;36:1-8.

17. Lin CC, Huang SC, Ou YK, Liu YC, Tsai CM, Chan HH, et al. Survival of patients aged over 80 years after Austin-Moore hemiarthroplasty and bipolar hemiarthroplasty for femoral neck fractures. Asian J Surg. 2012;35:62-6.

18. Sabnis B, Brenkel IJ. Unipolar versus bipolar uncemented hemiarthroplasty for elderly patients with displaced intracapsular femoral neck fractures. J Orthop Surg (Hong Kong). 2011;19:8-12.

19. van den Bekerom MP, Hilverdink EF, Sierevelt IN, Reuling EM, Schnater JM, Bonke $\mathrm{H}$, et al. A comparison of hemiarthroplasty with total hip replacement for displaced intracapsular fracture of the femoral neck: a randomised controlled multicentre trial in patients aged 70 years and over. J Bone Joint Surg (Br). 2010;92:1422-8.

20. Blomfeldt R, Törnkvist H, Eriksson K, Söderqvist A, Ponzer S, Tidermark J. A randomised controlled trial comparing bipolar hemiarthroplasty with total hip replacement for displaced intracapsular fractures of the femoral neck in elderly patients. J Bone Joint Surg (Br). 2007;89:160-5. 
21. Park KS, Oh CS, Yoon TR. Comparison of Minimally Invasive Total Hip Arthroplasty versus Conventional Hemiarthroplasty for Displaced Femoral Neck Fractures in Active Elderly Patients. Chonnam Med J. 2013;49:81-6.

22. Furlan AD, Pennick V, Bombardier C, van Tulder M. Editorial board, Cochrane back review group. 2009 updated method guidelines for systematic reviews in the Cochrane back review group. Spine (Phila Pa 1976). 2009;34:1929-41.

23. Landis JR, Koch GG. The measurement of observer agreement for categorical data. Biometrics. 1977;33:159-74.

24. Viera AJ, Garrett JM. Understanding interobserver agreement: the kappa statistic. Fam Med. 2005;37:360-3.

25. Higgins JPT, Green S. Cochrane Handbook for Systematic Reviews of Interventions Version 5.0.1 [updated September 2008]. The Cochrane Collaboration: John Wiley \& Sons Ltd, The Atrium, Southern Gate, Chichester, West Sussex P0198SQ, England. 2008.

26. Dorr LD, Glousman R, Hoy AL, Vanis R, Chandler R. Treatment of femoral neck fractures with total hip replacement versus cemented and noncemented hemiarthroplasty. J Arthroplasty. 1986;1:21-8.

27. Ravikumar KJ, Marsh G. Internal fixation versus hemiarthroplasty versus total hip arthroplasty for displaced subcapital fractures of femur-13 year results of a prospective randomised study. Injury. 2000;31:793-7.

28. Baker RP, Squires B, Gargan MF, Bannister GC. Total hip arthroplasty and hemiarthroplasty in mobile, independent patients with a displaced intracapsular fracture of the femoral neck. A randomized, controlled trial. J Bone Joint Surg Am. 2006;88:2583-9.

29. Mouzopoulos G, Stamatakos M, Arabatzi H, Vasiliadis G, Batanis G, Tsembeli A et al. The four-year functional result after a displaced subcapital hip fracture treated with three different surgical options. Int Orthop. 2008;32:367-73.

30. Hedbeck CJ, Enocson A, Lapidus G, Blomfeldt R, Törnkvist H, Ponzer S, et al. Comparison of bipolar hemiarthroplasty with total hip arthroplasty for displaced femoral neck fractures: a concise four-year follow-up of a randomized trial. J Bone Joint Surg Am. 2011;93:445-50.

31. Cadossi M, Chiarello E, Savarino L, Tedesco G, Baldini N, Faldini C, et al. A comparison of hemiarthroplasty with a novel polycarbonate-urethane acetabular component for displaced intracapsular fractures of the femoral neck: a randomised controlled trial in elderly patients. Bone Joint J. 2013;95-B:609-15.

32. Zhao Y, Fu D, Chen K, Li G, Cai Z, Shi Y, et al. Outcome of hemiarthroplasty and total hip replacement for active elderly patients with displaced femoral neck fractures: a meta-analysis of 8 randomized clinical trials. PLoS One. 2014;9:e98071.

33. Yu L, Wang Y, Chen J. Total hip arthroplasty versus hemiarthroplasty for displaced femoral neck fractures: meta-analysis of randomized trials. Clin Orthop Relat Res. 2012;470:2235-43.

34. Burgers PT, Van Geene AR, Van den Bekerom MP, Van Lieshout EM, Blom B, Aleem IS, et al. Total hip arthroplasty versus hemiarthroplasty for displaced femoral neck fractures in the healthy elderly: a meta-analysis and systematic review of randomized trials. Int Orthop. 2012;36:1549-60.

35. Hopley C, Stengel D, Ekkernkamp A, Wich M. Primary total hip arthroplasty versus hemiarthroplasty for displaced intracapsular hip fractures in older patients: systematic review. BMJ. 2010;340:c2332.

36. Reuling EM, Sierevelt IN, van den Bekerom MP, Hilverdink EF, Schnater JM, van Dijk CN, et al. Predictors of functional outcome following femoral neck fractures treated with an arthroplasty: limitations of the Harris hip score. Arch Orthop Trauma Surg. 2012;132:249-56.

37. Liao L, Zhao J, Su W, Ding X, Chen L, Luo S. A meta-analysis of total hip arthroplasty and hemiarthroplasty outcomes for displaced femoral neck fractures. Arch Orthop Trauma Surg. 2012;132:1021-9.

38. Zi-Sheng A, You-Shui G, Zhi-Zhen J, Ting Y, Chang-Qing Z. Hemiarthroplasty vs primary total hip arthroplasty for displaced fractures of the femoral neck in the elderly: a meta-analysis. J Arthroplasty. 2012;27:583-90.

39. Bilgen O, Karaeminogullari O, Küleçioglu A. Results of conversion total hip prosthesis performed following painful hemiarthroplasty. J Int Med Res. 2000;28:307-12.

40. Sen D, Alsousou J, Fraser J. Painful hemiarthroplasty due to acetabular erosion: a new technique of treatment. J Bone Joint Surg (Br). 2009;91:530-2.

41. Sharkey PF, Rao R, Hozack WJ, Rothman RH, Carey C. Conversion of hemiarthroplasty to total hip arthroplasty: can groin pain be eliminated? J Arthroplasty. 1998;13:627-30.

42. D'Arcy J, Devas M. Treatment of fractures of the femoral neck by replacement with the Thompson prosthesis. J Bone Joint Surg (Br). 1976;58:279-86.
43. Gebhard JS, Amstutz HC, Zinar DM, Dorey FJ. A comparison of total hip arthroplasty and hemiarthroplasty for treatment of acute fracture of the femoral neck. Clin Orthop Relat Res. 1992;282:123-31.

44. Coates RL, Armour P. Treatment of subcapital fractures by primary total hip replacement. Injury. 1979;11:132-5.

45. Leonardsson O, Kärrholm J, Åkesson K, Garellick G, Rogmark C. Higher risk of reoperation for bipolar and uncemented hemiarthroplasty. Acta Orthop. 2012;83:459-66.

46. Suh KT, Moon KP, Lee HS, Lee CK, Lee JS. Consideration of the femoral head cartilage thickness in preoperative planning in bipolar hemiarthroplasty. Arch Orthop Trauma Surg. 2009;129:1309-15.

47. Berry DJ, von Knoch M, Schleck CD, Harmsen WS. Effect of femoral head diameter and operative approach on risk of dislocation after primary total hip arthroplasty. J Bone Joint Surg Am. 2005;87:2456-63.

48. Enocson A, Hedbeck CJ, Tidermark J, Pettersson H, Ponzer S, Lapidus LJ. Dislocation of total hip replacement in patients with fractures of the femoral neck. Acta Orthop. 2009;80:184-9.

49. Byström S, Espehaug B, Furnes O, Havelin LI, Norwegian Arthroplasty Register. Femoral head size is a risk factor for total hip luxation: a study of 42,987 primary hip arthroplasties from the Norwegian Arthroplasty Register. Acta Orthop Scand. 2003;74:514-24.

\section{Submit your next manuscript to BioMed Central and take full advantage of:}

- Convenient online submission

- Thorough peer review

- No space constraints or color figure charges

- Immediate publication on acceptance

- Inclusion in PubMed, CAS, Scopus and Google Scholar

- Research which is freely available for redistribution

Submit your manuscript at www.biomedcentral.com/submit
C Biomed Central 